\title{
Surfactant, Mechanical Ventilation or CPAP for Treatment of Early Respiratory Failure in Preterm Infants: A Continuing Conundrum?
}

\author{
SUNIL SINHA \\ Professor of Pediatrics, University of Durham and James Cook University Hospital, Middlesbrough, United Kingdom. \\ sunil.sinha@stees.nhs.uk
}

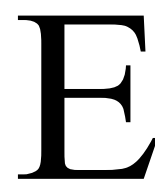

xogenous surfactant replacement therapy and mechanical ventilation (MV) still remain the 'standard of care' while treating preterm infants with respiratory failure. However, this requires endotracheal intubation - an invasive procedure associated with complications. Moreover, the skills required to intubate very small babies are not universally available and may vary among the health care professionals. This has led to increasing interest in the use of non-invasive form of respiratory support which do not require placement of an endotracheal tube. These non-invasive respiratory support methods include: Continuous Positive Airway Pressure (CPAP), Nasal Intermittent Positive Pressure Ventilation (NIPPV) and High Flow Nasal Cannulae (HFNC).

The application of CPAP helps keep the upper airway open during both inspiration and expiration, and improve the functional residual capacity. Two large randomised controlled trials comparing CPAP with traditional intubation and ventilation have recently been published. In the first trial, 610 infants of between 25 to 28 weeks gestation were randomized to receive either early CPAP or Intubation and Ventilation without surfactant (CPAP or Intubation (COIN Trial)) [1]. Although appearing to be better in short term, when assessed at 36 weeks gestation, CPAP did not show any advantage in terms of survival or chronic lung disease (CLD) at the time of discharge. Moreover, babies in CPAP group had somewhat higher incidence of pneumothorax as compared to ventilation group. Another recently published trial, Surfactant Positive Pressure and Pulse Oximetry Randomised Trial (SUPPORT Trial) [2], enrolled 1316 infants born between 24 to 27 weeks gestation to receive either early CPAP in the delivery room without any surfactant (CPAP group) or intubation and surfactant treatment within one hour after birth (ventilation group). The primary outcome of death or chronic lung disease at 36 weeks did not differ between the two groups (47\% in CPAP group $v s 51.0 \%$ in ventilation group). There was also no difference in the incidence of pneumothorax. These two trials have recruited 1926 infants between them and showed that almost half of them could be successfully managed on early CPAP who otherwise might have been candidate for mechanical ventilation. The downside of the story is that half of the infants enrolled in these studies particularly of those between 24-28 weeks' gestation failed CPAP treatment. It can be argued that such babies might have been disadvantaged because of delay in the 'standard care' of treatment and this has prompted some investigators to assess the effect of early surfactant through intubation followed by quick extubation to nasal CPAP (INSURE) technique. The data on this approach has been limited. Recently, the results of a large randomised trial (VON Trial) [3] become available in abstract form. In this trial, 648 infants between 26-29 weeks' gestation were randomized in three groups: prophylactic surfactant and mechanical ventilation, INSURE, and CPAP with selective intubation. The trial reported no difference in death or chronic lung disease at 36 
weeks between the three groups and similarly, there were no differences in the incidence of pneumothorax. The results from another study just prior to this also reported no difference in need for mechanical ventilation, BPD or pneumothorax among infants born at 24-28 weeks gestation and rando-mized to receive prophylactic or early selective surfactant with nasal CPAP, suggesting early rescue surfactant is as good as prophylactic surfactant [4]. Thus, the results are confusing and evidence so far does not tell us the full story. The onus is on the clinicians to improve their skills in selecting the right mode of treatment for individual infants, optimising different modes of treatment and collecting long term safety and clinical outcome data. In this issue of the journal, Tsakildis, et al. [5] describe the advantages of surfactant administration followed by brief ventilation and extubation (Intubation-Surfactant-Extubation-Insure). Their findings are in line with previous published studies but do not provide any new information. Further research is still needed to answer many questions, both in the short and long terms, related to the efficacy and safety of various forms of respiratory support currently being practiced in neonatal units.
Funding: None

Competing interests: None stated.

\section{REFERENCES}

1. Morley CJ, Doyle LW, Brion LP, Hascoet JM, Carlin JB. For COIN Trial investigators. Nasal CPAP or intubation at birth for very preterm infants. N Engl J Med. 2008; 358:700-8.

2. SUPPORT Study Group of the Eunice Kennedy Shriver NICHD Neonatal Research Network. Early CPAP versus surfactant in extremely preterm infants. N Engl J Med. 2010;362:1970-9.

3. Dunn M, Kaempf J, de Klerk A, de Klerk R, Reilly M, Howard D, et al. Delivery room management of preterm infants at risk for Respiratory Distress Syndrome (RDS). Proceedings of the Pediatric American Society; 2010 May 1; Vancouver, Canada. Available from: http://www. abstracts2view.con/pas/view.php?nu=PAS10L1660. Accessed on January 25, 2010.

4. Sandri F, Plavka R, Simeoni U; CURPAP Advisory Board. The CURPAP study: an international randomized controlled trial to evaluate the efficacy of combining prophylactic surfactant and early nasal continuous positive airway pressure in very preterm infants. Neonatology. 2008;94:60-2.

5. Tsakalidis C, Kourti M, Karayianni P, Rallis D, Porpodi M, Nikolaidis N. Early rescue administration of surfactant and nasal continuous positive airway pressure in preterm infants $<32$ weeks gestation. Indian Pediatr. 2011;48:601-5. 